of the student easier by concentrating his thoughts upon one subject instead of dissipating his attention among many subjects. If a man wishes to accomplish intellectual labor he seeks instinctively to apply himself wholly to that one task until it is completed. The capacity for sustained effort is the power by which the man surpasses the child. The child needs constant change and variety, and the system, which we have had in our school, of running from one lecture to another and from one laboratory to another, appears to many of us more suitable for school children than for young men studying medicine, and we expect, therefore, the new plan of studies to be justified by its results.

Here we must pause, although we have merely touched upon general principles and looked at a few details as illustrations. It seems to me that the whole problem of medical education is just now one of the most interesting and important ever presented in the history of American universities. If I have stimulated your interest in it I am rewarded.

Before I close I will venture to address to those of you who are to-morrow to receive your medical degrees a few words upon the deeper signification of your profession. This is not the time to enter into a discussion of the assumed antagonism between practical science and Christian faith. Each year brings the two into closer and more helpful relationship and increases their mutual understanding. The dignified agnosticism of Huxley and the lofty spiritualism of Brooks meet in the common conviction that the growth and development of man to a higher and better physical and spiritual life is alone what makes existence worthy.

We are living in an epoch of great scientific discovery and of consequent material progress, which among its many results includes numerous new facilities for inter- course between nations. In contemplating these facilities one recalls how great a part the free intercourse under the great Roman Empire played in the first spread of Christianity, so that one involuntarily asks: Is not science now aiding the same cause in a similar way? Science does more. By its steadfast pursuit of truth; by its broadminded ability to acknowledge the truth whatever found; by its freedom from narrow dogmatism on the one hand, and from ignorant materialism on the other, science can do a noble work in the great battle between good and evil in the world.

The antagonism of science and religion is unreal. Our intellectual Quixotes take it for one of their windmills, but I very much doubt if it be more than the phantom of a windmill. When you, young men, begin your life's campaign, fight real foes, be blind to threatening phantoms and deaf to their noisy shibboleths. Attack real diffculties. Remember always that as physicians you will have to help others, and that it will be peculiarly your obligation to uphold the standard of faithful service and to defend what I may call the creed of science: that the advancement of knowledge is a duty because it serves mankind. Faithful scientific research is Christian service.

Charles Sedghick Minot.

\section{LORD KELVIN'S ADDRESS ON THE AGE OF THE EARTH AS AN ABODE FITTED FOR LIFE.}

II.

A THrRD line of argument relative to the habitable era of the earth is drawn from the theoretical age of the sun. After stating the probability that, if sunlight was ready, the earth was ready both for vegetable and animal life within a century, or at least a few centuries, after the consolidation of the earth's surface, Lord Kelvin inquires whether the sun was ready, and re- 
plies: * "The well-founded dynamical theory of the sun's heat carefully worked out and discussed by Helmholtz, Newcomb and myself, says No if the consolidation of the earth took place as long [ago] as 50 million years; the solid earth must in that case have waited 20 or 50 [30?] million years for the sun to be anything nearly as warm as he is at present. If the consolidation of the earth was finished 20 or 25 million years ago the sun was probably ready, though probably not then quite so warm as at present, yet warm enough to support some kind of vegetable and animal life on the earth." Here is an unqualified assumption of the completeness of the Helmholtzian theory of the sun's heat and of the correctness of deductions drawn from it in relation to the past life of the sun. There is the further assumption, by implication, that no other essential factors entered into the problem. Are these assumptions beyond legitimate question? In the first place, without questioning its correctness, is it safe to assume that the Helmholtzian hypothesis of the heat of the sun is a complete theory? Is present knowledge relative to the behavior of matter under such extraordinary conditions as obtain in the interior of the sun sufficiently exhaustive to warrant the assertion that no unrec. ognized sources of heat reside there? What the internal constitution of the atoms may be is yet an open question. It is not improbable that they are complex organizations and the seats of enormous energies. Certainly, no careful chemist would affirm either that the atoms are really elementary or that there may not be locked up in them energies of the first order of magnitude. No cautious chemist would probably venture to assert that the component atomecules, to use a convenient phrase, may not have energies of rotation, revolution, position and be otherwise comparable in kind and

*Science, May 19, 1899, p. 711 . proportion to those of a planetary system. Nor would he probably feel prepared to affirm or deny that the extraordinary conditions which reside in the center of the sun may not set free a portion of this energy. The Helmboltzian theory takes no cognizance of latent and occluded energies of an atomic or ultra-atomic nature. A ton of ice and a ton of water at a like distance from the center of the system are accounted equivalents, though they differ notably in the total sum of their energies. The familiar latent and chemical energies are, to be sure, negligible quantities compared with the enormous resources that reside in gravitation. But is it quite safe to assume that this is true of the unknown energies wrapped up in the internal constitution of the atoms? Are we quite sure we have yet probed the bottom of the sources of energy and are able to measure even roughly its sum-total ?

There are some things hereabouts in the instruction we receive that puzzle us with our geological limitations :

1. We are taught that there.is a certain critical temperature for every substance above which it takes the gaseous form, and no amount of pressure can reduce it to the liquid or solid state.

2. We are taught that gases are compressible to an indefinite extent provided their temperatures be above the critical point.

3 . We are told the temperature of the. interior of the sun is probably above the critical temperature of any known substance, and hence that all the material of the interior of the sun is probably gaseous.

4. We are taught that so long as the substances of the sun remain in the gaseous. condition the temperature of the sun must rise from increased self-compression. It cannot, therefore, fall to the critical temperature of the component substances, and must, therefore, continue in the gaseous state and grow hotter and hotter. 
5. We are taught that gravity varies inversely as the square of the distance. As the distance between any two particles is halved, their mutual attraction is raised fourfold. Perpetual halving would cause the attraction to mount up toward infinity.

In the sun, then, there seems to bo this interesting combination : (1) a gaseous mass already above the critical temperature growing hotter and hotter by self.compression and bound to grow hotter and hotter so long as it remains a gas ; and it is bound to remain a gas until it falls below the critical temperature, which it cannot do while it continues to grow hotter; (2) a gravity that increases four-fold with every halving of distance and that is bound to increase so long as concentration continues, and concentration must continue while the substance is a gas and the gravitative pressure increases.

What is the logical outcome of this kind of logic and this sort of a combination? A geologist begins to grow dizzy contemplating such thermal possibilities. Why should not atoms, atomecules, and whatever else lies below, one after another have their energies squeezed out of them; and the outer regions be heated and lighted for an unknowable period at their expense?

There was a tine when the chemical theory of the sun's heat was fairly satisfactory to the scientists of the day, but its inadequacy appeared in time. There followed a period in which the meteoroidal theory of the sun's origin was deemed adequate, but its defects soon became apparent. There has followed the contractional theory, the validity of which is perhaps not less questioned now than was the validity of the chemical and meteoroidal hypotheses in their day of acceptance, but, judging from the past, it may easily appear in the future that the Helmholtzian theory is inadequate in some measure not unlike its predecessors.
But assuming, as we are wont to ao, that the limits of our present knowledge are a definition of the facts, has the evolution of the sun been worked out with such definiteness and precision as to give a determinate and specific history of its thermal stages from beginning to end? It is one thing to tell us, on the basis of the contractional theory, that the total amount of thermal energy originally potential in the system is only equal to so many million times the present annual output, but it is quite a different thing to give a specific statement of the actual time occupied by the sun in the evolution and discharge of this amount of heat and to define its successive stages. It is with this actual history that we are specially concerned. The distribution of the computed heat in time may have been such hypothetically as to shorten the period of its expenditure not simply to 20 or 25 millions of years, as indicated by Lord Kelvin, but to four or six millions of years as deduced by Ritter.* On the other hand, the dealing-out of this amount of heat may hypothetically have occupied a period many times the 20 or 25 million years postulated. It seems altogether necessary to determine specifically the distribution of the heat in time before any approach to a satisfactory application to geological history can be made. The period of 20 or 25 million years named can have little moral guiding force until this problem is solved. But the literature of the subject shows an almost complete neglect of this consideration. While certain of the physicists and astronomers have been instructing us ' $e$ superiore loco', they seem, with very rare exceptions, to have overlooked this vital factor in the case. Even in computing the sum-total of heat they have, for the most part, heretofore neglected the central condensation of the sun and in their computations have sub-

\footnotetext{
* Astrophysical Journal, December, 1898 ; Journal of Geology, p. 93, No. 1, Vol. VII., 1899.
} 
stituted a convenient homogeneity. This is recognized in a more recent number of Science (May 26) in the article by Dr. See, in which he offers a correction which involves an extension of the previously assigned output (18 million times the present annual radiation) to about 32 million times the annual radiation. But even in making this correction he neglects to consider the distribution of this heat in time, and leaves upon the reader the impression that the life-history of the earth was limited to 32 million years. Assuming the correctness of his computations, the past thermal discharge of the sun is merely limited to 32 million times the present annual expenditure. For aught that appears to the contrary, the actual output of this heat may have been spread over any assignable number of years. It is obvious upon consideration that a certain distribution of this past heat would favor longevity of life upon the earth, provided it could exist with a more limited heat supply than the sun is now yielding. On the other hand, it is equally evident that if the supply be distributed in certain other ways, either in the nature of excessive prolongation or of excessive concentration, the life era will be shortened. Doubtless the admonitory physicists have assumed that it was sufficient for the gross purposes of restraining geologists within due limits to determine the total amount of heat without assiduously considering the actual facts relative to its distribution, but some of us are unwilling to accept this loose method of dealing with the problem, since there are resources of application of which our physical friends have perhaps not taken cognizance. For example:

1. If at a certain stage in the evolution of the sun it occupied essentially all the space within the earth's orbit, and was giving forth one-half as much heat per year as now, it would possibly have sufficed for the needs of life upon the earth essentially as well as at present, without the assumption of any change in the constitution of the earth or of its atmosphere. For, on this supposition, approximately one-half of the space into which the earth radiated its heat would be blanketed by the sun and the heat thrown forth from the earth would be measurably caught and returned, and hence the loss of heat by radiation from the surface of the earth would have been reduced.

2. If, at the same time, we suppose that the material now concentrated in the outer planets was dispersed in a broad nebulous or meteoric belt mantling the heavens on the opposite side, another means would be provided by which some portion of the heat radiated away would be caught and returned to the earth, and a further small reduction in the original receipt of heat from the sun may be made consistently with the existence of life. This outer belt would be very tenuous and its effects correspondingly meagre, but it is a factor to be considered in a complete set of assumptions.

3. If, in addition to this, we make the consistent assumption that many other bodies of the heavens which are now concentrated into suns or into dark bodies were then in a more dispersed nebulous or meteoroidal condition, the general space of the stellar universe would be partially mantled, and there would be less free scope for the escape of the heat, solar and terrestrial alike, which is now freely lost through the open regions of space. It may be conceived that there was a common blanketing of the heavens by the dispersal of its now concentrated matter. This conception is the logical companion of the supposed dispersal of the solar matter. If the volume of matter in the stellar universe could be supposed to be sufficient, it might be so distributed hypothetically as to mantle the whole heavens and largely prevent the escape of central heat outwards, just as the 
central heat of the more concentrated bodies is conserved at the present time. Under this conception the history of the stellar universe may be characterized as a progressive clearing-up of nebulosities and meteoroidal dispersions and the concentration of its matter about certain points, leaving between vast open spaces through which heat is now radiated away with a facility un. realized in the earlier stages. The quantitative value of such a suggestion must be left to the determination of astronomers who have the best data for forming a conjecture as to the ratio of matter to space in the stellar universe and as to the possibilities of its dispersion at a period coincident with the earlier stages of the earth's history.

4. A modification of the conditions assumed in the foregoing paragraphs may be postulated in which the earth is regarded as having made its early growth within the primordial meteoric aggregate, perhaps a great flattened meteoric spheroid, which initially extended beyond Neptune in nebular fashion and whose present attenuated rẻpresentative may, perhaps, be found in the zodiacal light. In this case the thermal environment of the early earth was that furnished by the interior of the spheroid, though far out from ihe center. The conditions only became external gradually as the growth of the planets exhausted the peripheral portion of the meteoric spheroid.

5. The foregoing hypotheses, which do not seem to be so completely out of accord with the possibilities of the case as to be inadmissible tentatively in the absence of a positive solution of the early terrestrial environment, are concerned with the external relations of the earth. If we turn to the earth itself it may be remarked that the nature of its atmosphere very radically conditions the amount of heat requisite for the support of life. Dr. Arrhenius has recently made an elaborate computation relative to the thermal influence of certain farc- tors of the atmosphere and has arrived at the conclusion that an increase of the atmospheric carbon dioxide to the amount of three or four times the present content would induce such a mild climate in the polar regions that magnolias might again flourish there as they did in Tertiary times. On the other hand, he concluded that a reduction of less than $50 \%$ would induce conditions analogous to those of the glacial period of Pleistocene times. The vast quantities of carbon dioxide represented in the carbonates and carbonaceous deposits of the earth's crust imply great possibilities of change in the constitution of the atmosphere of the earth in respect to this most critical element.

6 . But there are more radical considerations that relate to the early thermal history of the earth. To be sure, if we are forced to adopt the hypothesis of a whitehot liquid "earth, with all its extravagant expenditures of energy in the early youth of the earth, we can take no advantage of these possible resources, but under the supposition that the meteorites gathered in with measurable deliberation, it is theoretically possible to find conditions for a long maintenance of life on the earth, with little or no regard to the amount of heat which the early sun sent to it. In the earliest stages of the aggregation of the earth under this hypothesis, while it was yet small, it can scarcely be supposed to have been habitable, because its mass was not sufficient to control the requisite atmospheric gases, but when it had grown to the size of Mars, that is to a size representing about $\frac{1}{10}$ of its present aggregation, or, to be safe, when it had grown to twice the size of Mars, or about one-fifth of its present mass, it would have been able to control the atmospheric gases and water, and, so far as these essential items are concerned, it would have presented conditions fitted for the presence of life. At this stage the 
larger portion, four-fifths by assumption, of the matter of the earth would yet be in the meteoroidal form and doubtless more or less closely associated with the growing nucleus. If the infalling of this four-fifths of the material of the earth were duly timed, so as to be neither too fast nor too slow, it would give by its impact upon the atmosphere of the earth a sufficiency both of heat and of light to maintain life upon the surface of the earth. The plungingdown of these meteorites upon the surface might be more or less destructive to the life, but only proportionately more so than the fall of meteorites to-day. It would not be necessarily fatal to life, especially oceanic life; indeed, the strokes of the meteorites might not be more inimical to the perpetuity of any given form of life then than are the attacks of its numerous enemies to-day. It was only another form of jeopardy. The latitude as to variation of rate of infall would be rather large. The infall must not have been so rapid as to have given a universal surface heat above $100^{\circ} \mathrm{C}$. The life of hot springs crowds close upon this upper limit; as Lord Kelvin has indicated. The infall must not have been so slow as to have permitted the surface heat to fall universally below $0^{\circ} \mathrm{C}$, making allowance for other sources. These other sources might have permitted the meteoric supply to fall considerably below the quantity represented by a surface temperature of $0^{\circ} \mathrm{C}$. Between this indeterminable low point and a supply equivalent to $100^{\circ} \mathrm{C}$., similarly qualified, there is a quite wide range. Those who have insisted upon the precipitate infalling of meteorites at such a rate as to reduce the earth to a nebulous condition will probably not feel entitled to doubt the adequacy of this source of light and heat. They can only question the possibility of the meteorites falling in slowly enough to permit the coincident presence of life on the earth.
This hypothesis starts life at a period when the earth was one-fifth grown and prolongs it throughout the rather slow gathering-in of the last four-fifths of the earth's mass, and hence gives to the earth a long era of autogenic life conditions.

Now, if a hypothesis relative to the early constitution and the growth of the rest of the solar system concordant with this be entertained, that is, a constitution of a predominantly meteoroidal rather than a gaseous condition, and of a slow rather than a precipitate aggregation, it will, perhaps, appear that the output of heat by the sun in the stages concurrent with this autogenic life period of the earth may have been small. The autogenic thermal era of the earth may thus have corresponded to a period of slight thermal loss by the sun.

As time went on the ingathering of the terrestrial meteorites gradually became more and more distant from one another (since the scattered material was progress. ively exhausted by previous infalls), while the central or solar aggregation was yet only in its early stages and was gradually increasing in heat. If this increase was in a ratio somewhat proportionate to the decline of the autogenic heat of the earth an equalizing compensation might result, and the earth gradually pass from the relatively independent autogenic thermal stage to the dependent solar stage which has continued to the present. Thus, by the prolonged coincidence of increase on the one side with decrease on the other, the life history of the earth may have been transferred from meteoroidal to solar dependence without such a radical disruption of continuity as to have been generally destructive.

This speculation may seem at first thought to be far-fetched, and to be poised on a ticklish combination of conditions, and it may, indeed, prove, when critically studied, to be really so, but yet it is submitted that it follows along coherent lines connected 
ultimately with the fundamental proposition that dispersed meteoroidal matter might gather in slowly rather than precipitately. On this point hangs all the law and the prophets.

If astronomers, physicists and mathematicians will jointly attack the formational history of the solar system stage by stage, following each stage out into details of time and rate, and taking full cognizance of all the alternatives that arise at each stage, it will then be possible, perhaps, to decide whether the conditions of the early earth were such as to require a large or a small amount of heat from the sun for the sustenance of life, and whether the sun was wasting heat prodigally in those days or conserving it for later expenditure. The present measure of the earth's needs may be no measure of its early needs. The sun's present expenditure may be no measure of its early expenditure.

In view of all these considerations, I again beg to inquire whether there is at present a solid basis for any 'sure assumption' with reference to the earth's early thermal conditions, either internal or external, of such a determinate nature as to place any strict limitations upon the duration of life.

The latter part of the address is concerned with novel suggestions regarding the behavior of the supposed liquid surface of the earth in the stages just preceding its final solidification, involving a theory of the formation of the primitive surface rocks and of the original continents and ocean basins. The discussion of this I must leave to the petrologists, merely venturing the hint that they may find some occasion to reconstruct current petrological doctrines if they are to be brought into consonance with the new views offered.

The point of greatest general interest in this part of the address is the sharp statement of opinion that, if the original lava ocean had solidified equably in all its parts and produced a dead-level surface all around the globe, there seems no possibility that our present continents could have arisen to their present heights, or the ocean basins have sunk to their present depths, during twenty or twenty-five million years, or during any time however long. (Exact words previously quoted, p. 897.) Lord Kelvin adds: "Rejecting the extremely improbable bypothesis that the continents were built up of meteoric matter tossed from without, upon the already solidified earth, we have no other possible alternative than that they are due to heterogeneousness in different parts of the liquid which constituted the earth before its solidification" (this JoÜRnal, p. 706). This is as strong an assertion of the necessity of assuming crustal and sub.crustal heterogeneity as any advocate of a slow-accretion earth could wish. If the word 'liquid' and what follows be stricken out, and the words 'meteoroidal aggregate' be substituted in the sentence quoted, it will be a rather too strong statement of the alternative explanation which springs obviously from the meteorological hypothesis herein urged. It is not easy to see how such heterogeneity as is required to account for the continents and ocean basins could arise from a white-hot liquid-surfaced earth descended from a gaseous earth. To those who do not follow the petrological conceptions of the address, but who conceive the hypothetical lava ocean to have been one great solution, stirred by convectional and other currents and depositing crystals as supersaturation arose from change of temperature or from change in the solution itself, there seems not much more reason to suppose that its deposits would have been localized persistently on the sites of the present continents than to suppose that the present enveloping solution-the oceanif duly concentrated, would localize in a 
similar way the crystals which it would throw down. But this must be left to the petrologists. I cannot, however, express too strongly my appreciation of the value of Lord Kelvin's stalwart opinion respecting the incompetency of the thermal theory. of crustal deformation, since this, carries with itself, more remotely and occultly (pace Kelvin) an implication of like weakness in the theory of the white-hot earth itself.

University of Chicago.

\section{T. C. Chamberlin.}

\section{A DANGEROUS EUROPEAN SCALE INSECT NOT HITHERTO REPORTED; BUT AL- READY WELL ESTABLISHED IN THIS COUNTRY.*}

IN view of the activity and zealousness displayed by several of the European states in excluding American plants and fruits on the pretext of possible contamination with the San José scale, it is opportune perhaps to call attention to the fact that a dangerous and perhaps very dangerous European scale insect, Aspidiotus ostreceformis Curtis, has recently become well established in this country. This scale insect is very similar to the San José scale in general appearance and habit, and is liable to be almost, if not equally, as mischievous, judging from the examples of badly infested material which have come to this office for determination.

Aspidiotus ostreceformis is a well-known pest on various fruit trees in Europe, where it has a very wide distribution, but, strangely enough, in view of the ease of its importation on nursery stock, seems not to have gained lodgment in this country until comparatively recently. The first examples of

* The scale insect on pear and apple at Alameda, Cal., collected by Mr. Koebele and determined by Professor Cockerell as ostreæformis (Bul. 6, Tech. Ser., Div. Ent., U. S. Dept. Agric., p. 19.), is a case of wrong identification; the species is juglans-regix, as I have determined from examination of the original material. ostreceformis coming to this office from American sources were naturally confused with other species, being identified either as ancylus, juglans-regiae or forbesi, all near allies ; and while ostreceformis has undoubtedly been established in New York and Ohio for eight or ten years, and in other localities for shorter periods perhaps, its existence in this country has not hitherto been reported in print, and specific identification has only been established within the last year. In fact, so little is the species known that two experts in Coccidæ were prepared recently to describe as new an example, referred to below, coming to Dr. James Fletcher from Pocum, British Columbia. The fact that this material represented the European ostreaformis, now first shown to occur in this country, was fortunately determined by Mr. Theo. Pergrande in time, I believe, to prevent the publication of the new species.

Within the last few months material representing ostreceformis has come to this office and been determined by the writer very frequently, especially from the State of New York, where it seems to have become well established, notably in the vicinity of Geneva. No less that 15 lots of this scale insect have been determined from Geneva, N. Y., representing as food plants plum, cherry and apple. Most of this material has been communicated by $\mathrm{Mr}$. G. G. Atwood, either direct or through Mr. Felt. In one case the food plant is designated as 'European plum,' and the statement is made by Mr. Atwood that the scale occurs in numbers on this food plant, to its considerable injury. Additional localities in New York are: Rochester, on apple (H. C. Peck and V. H. Lowe) ; same locality, on plum (Dr. Peter Collier), and Millbrook, on pear (E. C. Butterfield, reported as badly infesting 7 pear and 12 plum trees imported eight years before from a German firm); Penfield, on apple (Felt) ; and also 